\title{
Ischemia-reperfusion injury of the isolated diabetic rat heart: Effect of the antioxidant stobadine
}

\author{
Zuzana Broskova, Zuzana Kyselova and Vladimir Knezl \\ Institute of Experimental Pharmacology and Toxicology, Slovak Academy of Sciences, Dúbravská cesta 9, 84104 Bratislava, \\ Slovak Republic
}

\begin{abstract}
The etiology of diabetic complications is strongly associated with increased oxidative stress. The aim of the present study was to evaluate the effect of the potent antioxidant stobadine (STB) on global ischemia-reperfusion cardiac injury in the rat model of diabetes mellitus (DM). Diabetes was induced by multiple low doses of streptozotocin. The effect of STB was compared with that of a high-dose of $\alpha$-lipoic acid (ALA). All experiments were performed on isolated Langendorff-perfused hearts 10 weeks after streptozotocin administration. Diabetic hearts showed to be more resistant to ischemia-reperfusion than the control hearts, as shown by the reduced number of reperfusion dysrhythmias. The effect of the therapy with ALA (100 mg/kg i.p., 5 times a week during 8 weeks) was comparable to that of STB $(25 \mathrm{mg} / \mathrm{kg}$ i.p., 5 times a week during 8 weeks) resulting in lowering the heart rate and coronary flow as well as the number of serious reperfusion dysrhythmias. Though the protective effect of STB on the reperfusion-induced dysrhythmias was comparable with that of ALA, both substances failed to enhance functional recovery of the diabetic rat heart.
\end{abstract}

Key words: Stobadine — $\alpha$-Lipoic acid — Diabetes — Ischemia-reperfusion — Heart

Abbreviations: ALA, $\alpha$-lipoic acid; CF, coronary flow; DM, diabetes mellitus; HR, heart rate; LVEDP, left ventricular end-diastolic pressure; LVDP, left ventricular developed pressure; STB, stobadine; STZ, streptozotocin; VF, ventricular fibrillation; VPB, ventricular premature beats; VT, ventricular tachycardia.

\section{Introduction}

Diabetes mellitus (DM) is not only a well-established risk factor for the development of ischemic heart disease (Hurst and Lee 2003), diabetic patients with myocardial infarction have moreover a higher short and long-term mortality than non-diabetic patients (Haffner et al. 1998).

Numerous studies have shown that increased oxidative stress is present in diabetic patients. Patients with diabetes have not only been found to have increased levels of circulating markers of free radical-induced damage but also reduced antioxidant defenses (Seghrouchni et al. 2002; Martin-Gallan et al. 2003). Hyperglycemia can induce oxidative stress

Correspondence to: Zuzana Brosková, Institute of Experimental Pharmacology and Toxicology, Slovak Academy of Sciences, Dúbravská cesta 9, 84104 Bratislava, Slovak Republic

E-mail: zuzana.broskova@savba.sk via several mechanisms, including glucose autoxidation, the formation of advanced glycation end-products (AGEs), and activation of the polyol pathway. There is considerable evidence to indicate that oxidative stress plays an important role in the etiology of diabetic complications, leads to endothelial cell damage and vascular dysfunction (Jay et al. 2006). Intensive control of blood glucose alone does not lead to a reduction in mortality caused by cardiovascular complications (Mannucci et al. 2009). As the pathogenesis of both diabetes and cardiovascular disease involves oxidative stress, the use of antioxidants is an appealing therapy.

A potent lipophilic antioxidant, $\alpha$-lipoic acid (ALA), has been shown to have a number of beneficial effects in many pathologies. The results of numerous pre-clinical and clinical studies have confirmed its efficacy in the treatment of diabetes-related complications such as peripheral neuropathy and cardiovascular autonomic neuropathy (Gouty et al. 2003; Tankova et al. 2004; Ziegler 2008). ALA exerts beneficial 
effects on endothelial function in diabetic patients (Heitzer et al. 2001). It has been found to attenuate mitochondriadependent cardiac apoptosis in the animal model of diabetes, thus exerting a protective role against the development of diabetic cardiomyopathy (Li et al. 2009).

The pyridoindole antioxidant stobadine (STB) was recognized to have significant antioxidant properties and the ability to scavenge free radicals, such as hydroxyl, peroxyl, and alkoxyl radicals (Stasko et al. 1990). Various studies have shown that STB is effective in oxidative stress-mediated pathologies. In the rat model of DM, STB showed a positive effect on diabetic cataract (Kyselova et al. 2005) or diabetic neuropathy, comparable with that of vitamin E (Skalska et al. 2008) or ALA (Skalska et al. 2010). Dietary supplementation with stobadine to diabetic rats prevented the development of dysfunction in the aorta and attenuated angiopathic and atherogenic processes in the aortic wall (Sotnikova et al. 2001). STB also prevented degenerative changes seen in diabetic sympathetic nerves of the vas deferens (Gunes et al. 2005) and significantly reduced oxidative damage of kidney tissue as well as diabetes-induced proteinuria and albuminuria (Stefek et al. 2002). Long-term treatment of diabetic animals with STB attenuated pathological changes in the diabetic myocardium by diminishing oxidative damage of myocardial tissue and reducing angiopathic and atherogenic processes in the myocardium (Kucharska et al. 2000; Stefek et al. 2000). These findings, along with the high oral bioavailability of STB, its toxic safety, as well as efficient detoxification pathways, render this drug a prospective agent in the prevention of late diabetic complications (for review see Juranek et al. 2010).

The present study is aimed at the analysis of the protective effect of repeated treatment with STB, compared with that of ALA, on global ischemia-reperfusion cardiac injury on using the streptozotocin (STZ)-induced DM rat model.

\section{Materials and Methods}

The study was approved by the Ethics Committee of the Institute and performed in accordance with the Principles of Laboratory Animal Care (NIH publication 83-25, revised 1985) and the Slovak law regulating animal experiments (Decree 289, Part 139, July 9th 2003).

\section{Experimental diabetes}

Male Wistar rats (250-300 g), 16 weeks old, obtained from the Breeding Facility of the Institute of Experimental Pharmacology and Toxicology SASc (Dobra Voda, Slovak Republic), were included in the study. Experimental diabetes was induced by multiple low doses of STZ dissolved in saline ( $20 \mathrm{mg} / \mathrm{kg}$ b.w. for 3 consecutive days i.v.) as described previously (Skalska et al. 2010). Control animals received the same volume of the vehicle alone. Afterwards, the rats were maintained under a $12 \mathrm{~h}$ light/dark cycle with free access to water and a standard laboratory diet.

\section{Experimental protocol}

Only animals with postprandial plasma glucose level $>20 \mathrm{mmol} / \mathrm{l}$ (measured on the eleventh day after STZ administration) were considered diabetic and were included in the study. The animals were allocated to four groups:

1) Control $(n=8)$ : nondiabetic rats treated with $0.9 \%$ sodium chloride solution i.p.,

2) $\mathrm{DM}(n=8)$ : diabetic rats,

3) $\mathrm{DM}+\mathrm{ALA}(n=8)$ : diabetic rats treated with ALA (100 mg/ $\mathrm{kg}$ b.w.) 5 times a week i.p., for 8 weeks prior to heart perfusion (started 11 days after STZ),

4) $\mathrm{DM}+\mathrm{STB}(n=8)$ : diabetic rats treated with STB $(25 \mathrm{mg} /$ kg b.w.) 5 times a week i.p., for 8 weeks prior to heart perfusion (started 11 days after STZ).

\section{Isolated heart preparation}

Ten weeks after STZ administration, the animals were anesthetized with thiopental (65 mg/kg b.w., i.p.) and heparinized (500 IU, i.v.). The hearts were canulated via the ascending aorta and then quickly removed and arranged for retrograde perfusion by the Langendorff technique, as described previously (Skrzypiec-Spring 2007). The hearts were perfused with a Krebs-Henseleit bicarbonate buffer at a constant pressure of $85 \mathrm{mmHg}$. The composition of the buffer was (in mmol/l): $\mathrm{NaCl}(118), \mathrm{KCl}(4.7), \mathrm{CaCl}_{2}$ (2.5), $\mathrm{NaH}_{2} \mathrm{PO}_{4}$ (1.18), $\mathrm{NaHCO}_{3}$ (25), and glucose (11.1); $\mathrm{pH} 7.40$, equilibrated with a gas mixture of $95 \% \mathrm{O}_{2}$ and $5 \%$ $\mathrm{CO}_{2}$ at $37^{\circ} \mathrm{C}$. The heart function was stabilized for $30 \mathrm{~min}$ followed by 30 -min global no-flow ischemia finalized by 30 min reperfusion. During ischemia the hearts were plunged into a non-oxygenated modified Krebs-Henseleit solution to maintain stable conditions.

\section{Analysis of heart function}

Left ventricular developed pressure (LVDP) was measured isovolumetrically with the use of a water-filled latex balloon, placed in the left ventricular chamber and connected to a pressure transducer. The balloon volume was adjusted to give a left ventricular end-diastolic pressure (LVEDP) of 3-7 $\mathrm{mmHg}$ at the beginning of the experiment. The following parameters were monitored: LVEDP, LVDP and heart rate (HR). Besides, coronary flow (CF) was measured by collection of perfusate outflow. For electrical activity monitoring, two contact electrodes for ECG recording were placed on the right atrium and the apex of the left ventricle. All parameters were continuously monitored on RFT-6 NEK 
recorder via RFT W 102 transducer (Germany). During reperfusion, ventricular dysrhythmias, i.e. VPB (ventricular premature beats), bradycardia ( $\mathrm{HR}<200$ beats/min), VT (ventricular tachycardia) and VF (ventricular fibrillation) were evaluated.

At the end of the reperfusion period, severe dysrhythmias (VF/VT) were evoked by electrical stimulation with the following parameters: current (fibrillation threshold $+50 \%$ ), train rate $4 \mathrm{~s}$, train duration $2 \mathrm{~s}$, stimulation rate $100 \mathrm{pps}$, duration $0.2 \mathrm{~ms}$ (electrostimulator ST-3 Medicor, Hungaria). Stimulating electrodes were attached to the epicardium of the right ventricle. The hearts with sustained VT/VF were not ellectricaly stimulated.

\section{Chemicals}

a-lipoic acid (Thioctacid ASTA Medica, Germany), stobadine dihydrochloride (IEP SAS Bratislava), streptozotocin (Sigma), thiopental (VÚAB Prague, Czech Republic). All other chemicals used were of analytical purity.

\section{Statistical analysis}

The results are presented as the mean \pm SEM. Statistical analyses were performed by using the unpaired Student's $t$-test or the two-way ANOVA with Bonferroni posttest. A value of $p<0.05$ was considered statistically significant.

\section{Results}

All diabetic animals manifested typical signs of diabetes, such as polyphagia, polydipsia, polyuria and elevated blood glucose levels (for glucose levels see Skalska et al. 2010).
Table 1. Frequency-pressure coefficient $(H R \times$ LVDP) before ischemia and after $30 \mathrm{~min}$ of reperfusion

\begin{tabular}{llc}
\hline & \multicolumn{2}{c}{ HR $\times$ LVDP } \\
\hline Group & Before ischemia & Reperfusion $30^{\prime}$ \\
\hline Control & $25572 \pm 831$ & $5307 \pm 1412$ \\
DM & $22568 \pm 1913^{*}$ & $9806 \pm 2450$ \\
DM+ALA & $20727 \pm 2063^{*}$ & $5561 \pm 1393$ \\
DM+STB & $18174 \pm 2447^{*+}$ & $4962 \pm 1178^{+}$ \\
\hline
\end{tabular}

$\mathrm{DM}$, diabetic group; $\mathrm{DM}+\mathrm{ALA}$, diabetic group treated with $\alpha$-lipoic acid; DM+STB, diabetic group treated with stobadine. Data expressed as mean \pm S.E.M., $n=8,{ }^{\star} p<0.05 v$ s. Control, ${ }^{+} p<0.05$ vs. DM group.

\section{Functional parameters}

The initial values of the contractile parameters HR and LVDP were not significantly different between the individual groups, however, as shown in Table 1, the rate-pressure product (HR $\times$ LVDP) was significantly lower in the ALA- and STB-treated diabetic groups in comparison with the control group. During reperfusion, the left ventricular function recovered slowly after its total elimination caused by ischemia. After 30 min of reperfusion, the recovery of contractility was highest in the $\mathrm{DM}$ group and lowest in the DM+STB group.

In comparison with the initial HR in the control group, which reached $282.9 \pm 11.8$ beats/min, the HR in the DM group was partially reduced, while treatment with ALA or STB significantly lowered this value (Figure 1). During reperfusion, the HR in the control group was relatively stable and at the end of reperfusion it reached $81 \%$ of its preischemic value. In contrast, in all diabetic groups, a radical

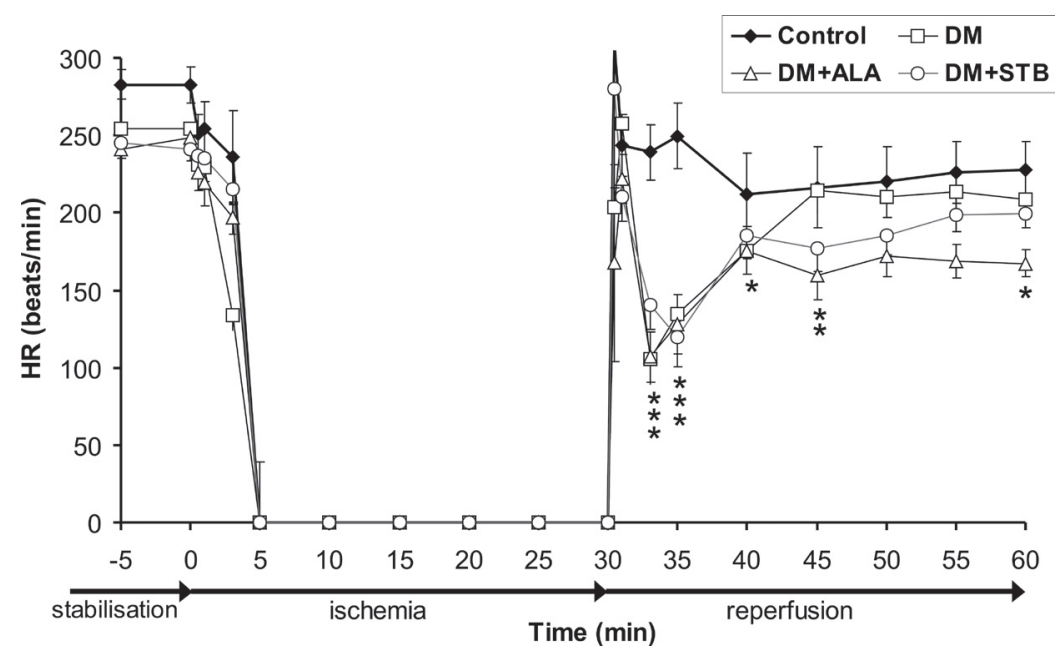

Figure 1. Heart rate (HR) during the experiment. DM, diabetic group; DM+ALA, diabetic group treated with $\alpha$-lipoic acid; DM+STB, diabetic group treated with stobadine. Data are means \pm S.E.M.; $n=8 ;{ }^{*} p<0.05,{ }^{* *} p<0.01 ;{ }^{* *} p<0.001 v$ s. Control. 
reduction of HR to bradycardia level was seen from the 3rd to 5 th minute of reperfusion. At the end of experiment, DM and DM+STB groups reached approximately $82 \%$ of their pre-ischemic values, while DM+ALA only $70 \%$.

During ischemia as well as reperfusion, the hearts underwent a typical pathological increase in LVEDP, which in the control group, peaked in the 16th minute of ischemia and in the 3rd minute of reperfusion (data not shown). Other experimental groups failed to influence this course of LVEDP, except the DM group, where LVEDP was significantly reduced during the first 15 minutes of ischemia and in the very beginning of the reperfusion. In comparison with the DM group, LVEDP in the group DM+STB was non-significantly higher during reperfusion $(p=0.055,20$ th minute of reperfusion).

The initial values of CF in all groups were not significantly different. In the control group, during reperfusion, $\mathrm{CF}$ relatively quickly reached its preischemic value and did not markedly change till the end of the experiment (see Table 2). CF during reperfusion was not significantly changed in the $\mathrm{DM}$ and DM+ALA group compared with the control group. However, STB administration to diabetic rats significantly reduced $\mathrm{CF}$ during reperfusion.

\section{Reperfusion dysrhythmias}

During the reperfusion period, ventricular dysrhythmias were evaluated from ECG recordings. In the control group, an average of $254 \pm 83 \mathrm{VPB}$ was found at the end of reperfusion (see Figure 2A), in the DM group, the number was not significantly different. Administration of ALA and of STB to diabetic animals significantly decreased the number of VPB to $102 \pm 20$ and $106 \pm 48$, respectively. Ventricular bradycardia lasted on the average $2.5 \pm 1.6 \mathrm{~min}$ in the control group. In the DM, DM+ALA and DM+STB groups, the duration of bradycardia was significantly increased in comparison with the control group to $14 \pm 3,28 \pm 3$, and $25 \pm 4$ min, respectively (Figure $2 \mathrm{~B}$ ).

As shown in Figure 3A, VT was sustained for $6.7 \pm$ $1.7 \mathrm{~min}$ in the control group, while in the DM group, VT lasted for $4.0 \pm 2.2 \mathrm{~min}$. Compared to the DM group, ad-
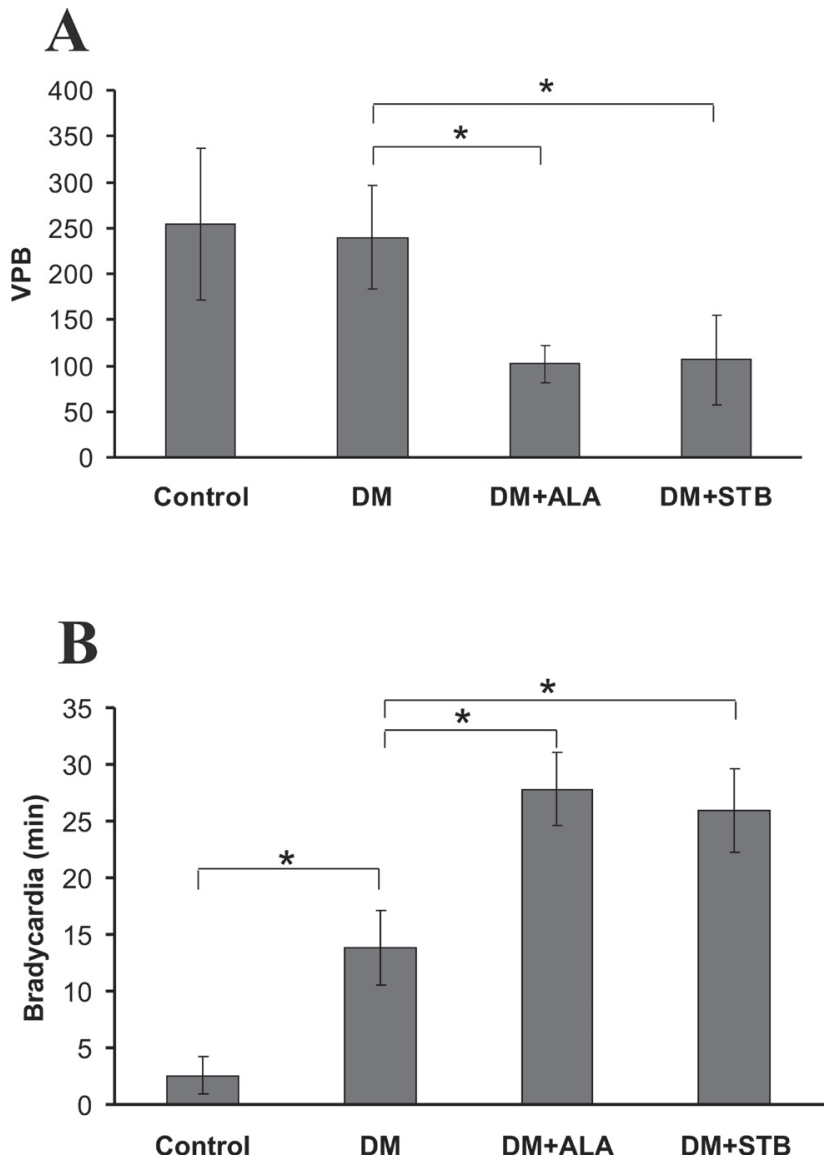

Figure 2. A. Number of ventricular premature beats (VPB) during reperfusion. B. Duration of bradycardia during reperfusion. Data are means \pm S.E.M., $n=8,{ }^{\star} p<0.05$. For abbreviation, see Figure 1 .

ministration of STB to diabetic rats significantly shortened the duration of VT to $0.6 \pm 0.4 \mathrm{~min}$, yet the reduction of $\mathrm{VT}$ in the DM+ALA group was not significant. Another life-threatening reperfusion dysrhythmia, VF, lasted for an average of $7.5 \pm 3.4 \mathrm{~min}$ in the control group. As shown in Figure 3B, the duration of VF was significantly reduced in the DM group to $0.5 \pm 0.4 \mathrm{~min}$ and even completely suppressed in the STB-treated diabetic group. The ALA

Table 2. Coronary flow before ischemia and after 10, 20 and 30 min of reperfusion

\begin{tabular}{lcccc}
\hline \multirow{2}{*}{ Group } & \multicolumn{3}{c}{ Coronary flow $(\mathrm{ml} / \mathrm{min})$} \\
\cline { 2 - 4 } & Before ischemia & Reperfusion $10^{\prime}$ & Reperfusion $20^{\prime}$ & Reperfusion $30^{\prime}$ \\
\hline Control & $12.8 \pm 1.1$ & $13.2 \pm 1.3$ & $11.8 \pm 1.4$ & $11.0 \pm 1.4$ \\
DM & $12.2 \pm 1.5$ & $11.4 \pm 1.2$ & $10.7 \pm 1.2$ & $9.9 \pm 1.1$ \\
DM+ALA & $11.9 \pm 1.0$ & $9.1 \pm 1.0$ & $8.8 \pm 1.0$ & $8.3 \pm 1.0$ \\
DM+STB & $11.5 \pm 1.1$ & $8.7 \pm 0.7^{*+}$ & $8.5 \pm 0.7^{*}$ & $8.2 \pm 0.7^{*}$ \\
\hline
\end{tabular}

$\mathrm{DM}$, diabetic group; DM+ALA, diabetic group treated with $\alpha$-lipoic acid; DM+STB, diabetic group treated with stobadine. Data expressed as mean \pm S.E.M., $n=8,{ }^{*} p<0.05 v$ s. Control, ${ }^{+} p<0.05 v$ s. DM group. 


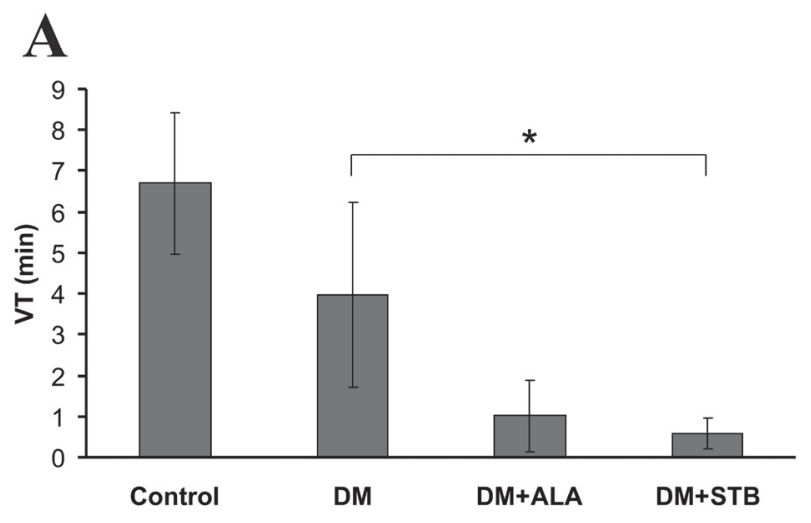

B

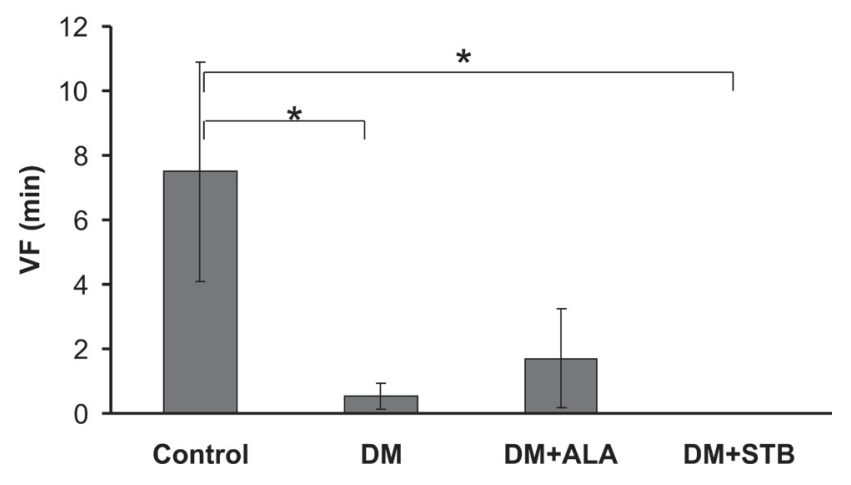

Figure 3. A. Duration of ventricular tachycardia (VT) during reperfusion. B. Duration of ventricular fibrillation (VF) during reperfusion. Data are means \pm S.E.M., $n=8,{ }^{*} p<0.05$. For other abbreviation, see Figure 1. treatment induced reduction in VT was not significant in comparison with the DM group.

In the control group, at least one episode of spontaneous serious VT or VF occurred in $63 \%$ of all hearts during reperfusion and electrically stimulated dysrhythmias were evoked in $37 \%$ of the control hearts (see Figure 4 ). In the diabetic group, the occurence of both spontaneous and ellectricaly evoked dysrhythmias was $63 \%$. In three animals of eight, dysrhythmias could not be evoked. In the ALA or STB-treated diabetic groups the occurrence of evoked dysrhythmias was the same but that of spontaneous, and so much more deleterious dysrhythmias, was lower in the DM+ALA group and they were completely absent in the $\mathrm{DM}+\mathrm{STB}$ group.

\section{Discussion}

The study showed the beneficial effect of longterm treatment with STB and ALA in reducing serious life-threatening reperfusion dysrhythmias of diabetic hearts. It is well-known that the risk of heart failure after myocardial infarction is higher in diabetic patients that in others (Lomblin et al. 2012). Hence, there is still the need to find an efficient therapy to prevent this phenomenon. The present study was aimed at exploring the therapeutic effect of the pyridoindole antioxidant STB and to compare it with that of ALA on functional parameters and dysrhythmias caused by ischemiareperfusion injury of isolated hearts of diabetic rats.

Hyperglycemia along with other metabolic derangements caused by diabetes is known to impair cardiac function by disrupting the balance between pro-oxidants and antioxidants at the cellular level (Jay et al. 2006). Diabetes is asso-

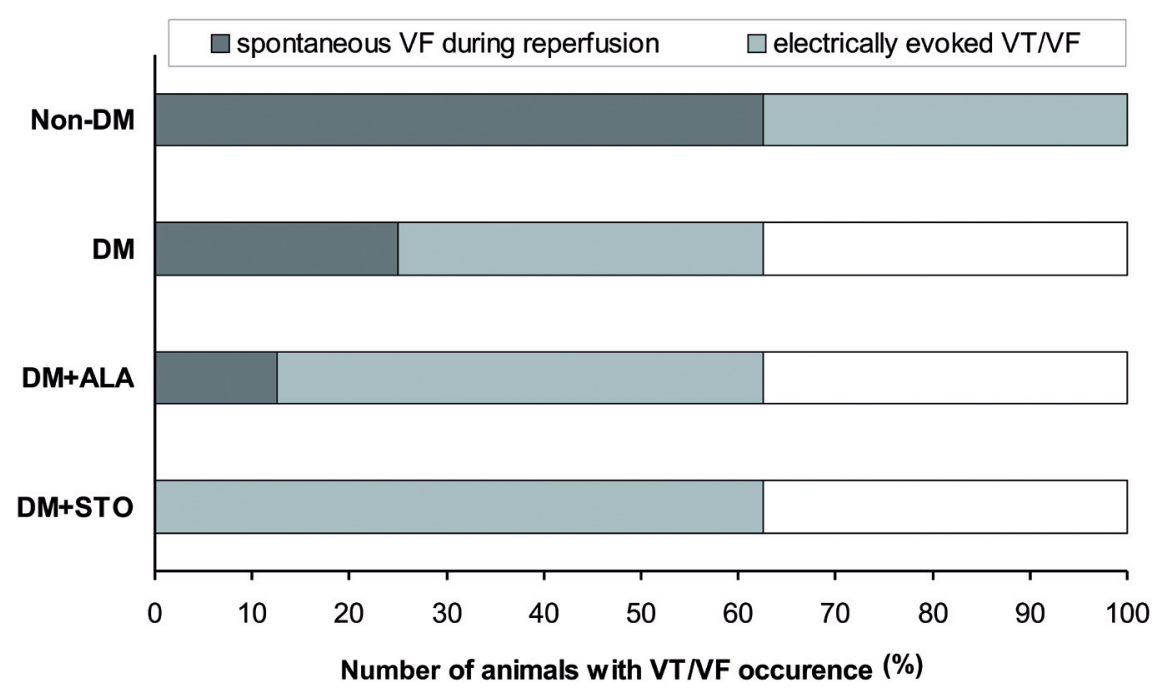

Figure 4. Number of animals in \% with occurrence of spontaneous VF/VT during reperfusion or electrically evoked VF/VT, calculated on total number of animals $n=8$ in each group. For abbreviation, see Figure 3. 
ciated with oxidative stress as shown by increased levels of various markers of oxidative stress such as hydroxyl radical (Fiordaliso et al. 2006), superoxid, nitrotyrosine (Okazaki et al. 2011), malondialdehyde (Guan et al. 2012) or lipid peroxidation products (Stefek et al. 2000). However, in our experiments, diabetic hearts showed to be more resistant to ischemia-reperfusion dysrhythmias than the control hearts, as shown on the reduced number of VPB, VT, VF during reperfusion and the lower susceptibility to electrically evoked dysrhythmias. At the same time, diabetic hearts were shown to increase the rate-pressure product at the end of reperfusion. The literature concerning this phenomenon in experimental diabetes studies is ambivalent. Diabetic animals were reported to be either more vulnerable (Bakth et al. 1986; Beatch and McNeill 1988; Tosaki et al. 1996) or more resistant to ischemia-reperfusion dysrhythmias (Kusama et al. 1992; Ravingerova et al. 2001; Zhang et al. 2002; Knezl at al. 2006; Matejikova et al. 2008). A possible explanation for the differing results may be the use of different experimental conditions, such as the duration and severity of the diabetic state, the nutritional status and cardiac function, the degree of ischemia, the type of metabolic substrate used and others (Paulson 1997; Galinanes and Fowler 2004).

The increased cardioprotection in diabetic hearts, as seen in our experiments, can be attributed to a decrease in the activity of the $\mathrm{Na}^{+} / \mathrm{H}^{+}$and $\mathrm{Na}^{+} / \mathrm{Ca}^{2+}$ exchangers and subsequent reduction of accumulations of $\mathrm{Na}^{+}$and $\mathrm{Ca}^{2+}$, limitation of acidosis and preservation of high-energy phosphates (Ramasamy and Schaefer 1999). Moreover, the antidysrhythmic effect in diabetic hearts can result from hyperglycemia, hypoinsulinemia or other metabolic changes of diabetes, such as hypothyroidism (Zhang et al. 2002).

As already mentioned, the etiology of diabetic complications is strongly associated with increased oxidative stress (Seghrouchni et al. 2002; Martin-Gallan et al. 2003) and it has been indicated that reactive oxygen species induced by high glucose may be involved, among others, in both deathreceptor- and mitochondrion-dependent apoptosis in the heart in vivo. Antioxidative treatment with ALA significantly suppressed apoptosis, suggesting that antioxidants may be a therapeutic option for preventing cardiovascular damage in DM in humans (Bojunga et al. 2004). In accordance with these findings, we used STB as a potent antioxidant agent to reduce the ischemia-reperfusion injury of isolated diabetic hearts. In the present study, treatment of diabetic rats with STB reduced the number of VPB, the duration of VT and completely eliminated VF during reperfusion in comparison with the DM and control group. This antidysrhythmic effect was even bigger than that seen in the ALA-treated group. In our previous study, STB and its two derivatives were found also to significantly reduce serious reperfusion dysrhythmias such as VF, which was completely suppressed in non-diabetic isolated hearts (Broskova and Knezl 2011).
In previous studies with isolated perfused hearts, 7-day treatment with ALA $(50 \mathrm{mg} / \mathrm{kg} /$ day i.p. $)$ as well as its acute administration $\left(5 \times 10^{-8} \mathrm{~mol} / \mathrm{l}\right.$ in the perfusion medium) induced an increase in CF (Ghibu et al. 2009; He et al. 2012). In our experiments, however, CF of diabetic hearts was reduced during reperfusion in comparison with the control group and ALA as well as STB treatment induced an even greater reduction in CF. This may be due to decreased HR and, in the experimental group treated with STB, also due to increased LVEDP during reperfusion. STB was also found to possess a-adrenolytic (Sotnikova et al. 1985) and antihistaminic effect (Bilcikova et al. 1990), so other mechanisms regulating resistance in coronary vasculature on the level of receptors may be involved as well.

According to numerous studies, it has been suggested that the use of HR-lowering drugs such as $\beta$-blockers to patients after acute myocardial infarction achieves clinical benefit exactly via the reduction in HR, thereby reducing myocardial oxygen demand. HR reduction may prevent ischemia and ischemic-related dysrhythmias (Kjekshus 1986; Hjalmarson et al. 1990). Thus the bradycardic effect of STB as well as ALA, shown in our experiments during reperfusion, seems to be beneficial. The correlation between the HR-lowering effect and the reduced duration of VT and VF during reperfusion suggests that the bradycardic effect of these substances may be an important factor in preventing serious reperfusion dysrhythmias.

Our study shows a protective effect of STB comparable with that of ALA on reperfusion-induced dysrhythmias in the diabetic rat heart. Yet these substances failed to improve the functional recovery after ischemia/reperfusion. The anti-dysrhythmic properties of STB may be mediated by its potent antioxidant protective effect, already shown in previous studies (Stasko et al. 1990; Stefek et al. 2000; Kucharska et al. 2000), while the HR-lowering effect seems also to be involved. Additional studies are to determine which other potential mechanisms of action come into play.

Acknowledgement. The study was supported by grants VEGA 2/0001/08, VEGA 2/0056/09 and APVV 51-017905.

\section{References}

Bakth S., Arena J., Lee W., Torres R., Haider B., Patel B. C., Lyons M. M., Regan T. J. (1986): Arrhythmia susceptibility and myocardial composition in diabetes. Influence of physical conditioning. J. Clin. Invest. 77, 382-395

http://dx.doi.org/10.1172/JCI112316

Beatch G. N., McNeill J. H. (1988): Ventricular arrhythmias following coronary artery occlusion in the streptozotocin diabetic rat. Can. J. Physiol. Pharmacol. 66, 312-317 http://dx.doi.org/10.1139/y88-053 
Bilcikova L., Matyas S., Bauer V. (1990): Effect of stobadine and histamine $\mathrm{H} 1$ and $\mathrm{H} 2$ blockers on histamine-induced contraction of guinea pig airways in vitro. Respiration 57, 104-108 http://dx.doi.org/10.1159/000195829

Bojunga J., Nowak D., Mitrou P. S., Hoelzer D., Zeuzem S., Chow K. U. (2004): Antioxidative treatment prevents activation of death-receptor and mitochondrion-dependent apoptosis in the hearts of diabetic rats. Diabetologia 47, 2078-2080 http://dx.doi.org/10.1007/s00125-004-1572-7

Broskova Z., Knezl V. (2011): Protective effect of novel pyridoindole derivatives on ischemia/reperfusion injury of the isolated rat heart. Pharmacol. Rep. 63, 967-974

Fiordaliso F., Cuccovillo I., Bianchi R., Bai A., Doni M., Salio M., De Angelis N., Ghezzi P., Latini R., Masson S. (2006): Cardiovascular oxidative stress is reduced by an ACE inhibitor in a rat model of streptozotocin-induced diabetes. Life Sci. 79, 121-129 http://dx.doi.org/10.1016/j.lfs.2005.12.036

Galinanes M., Fowler A. G. (2004): Role of clinical pathologies in myocardial injury following ischaemia and reperfusion. Cardiovasc. Res. 34, 113-120

Ghibu S., Lauzier B., Delemasure S., Amoureux S., Sicard P., Vergely C., Muresan A., Mogosan C., Rochette L. (2009): Antioxidant properties of alpha-lipoic acid: effects on red blood membrane permeability and adaptation of isolated rat heart to reversible ischemia. Mol. Cel. Biochem. 320, 141-148 http://dx.doi.org/10.1007/s11010-008-9916-0

Gouty S., Regalia J., Cai F., Helke C. J. (2003): Alpha-lipoic acid treatment prevents the diabetes-induced attenuation of the afferent limb of the baroreceptor reflex in rats. Auton. Neurosci. 108, 32-44 http://dx.doi.org/10.1016/j.autneu.2003.08.004

Guan S. J., Ma Z. H., Wu Y. L., Zhang J. P., Liang F., Weiss J. W., Guo Q. Y., Wang J. Y., Ji E. S., Chu L. (2012): Long-term administration of fasudil improves cardiomyopathy in streptozotocin-induced diabetic rats. Food Chem. Tox. 50, 1874-1882 http://dx.doi.org/10.1016/j.fct.2012.03.006

Gunes A., Ceylan A., Sarioglu Y., Stefek M., Bauer V., Karasu C. (2005): Reactive oxygen species mediate abnormal contractile response to sympathetic nerve stimulation and noradrenaline in the vas deferens of chronically diabetic rats: effects of in vivo treatment with antioxidants. Fundam. Clin. Pharm. 19, 73-79 http://dx.doi.org/10.1111/j.1472-8206.2004.00312.x

Haffner S. M., Lehto S., Ronnemaa T., Pyorala K., Laakso M. (1998): Mortality from coronary heart disease in subjects with type 2 diabetes and in nondiabetic subjects with and without prior myocardial infarction. N. Engl. J. Med. 339, 229-234 http://dx.doi.org/10.1056/NEJM199807233390404

He L., Liu B., Dai Z., Zhang H. F., Zhang Y. S., Luo X. J., Ma Q. L., Peng J. (2012): Alpha lipoic acid protects heart against myocardial ischemia-reperfusion injury through a mechanism involving aldehyde dehydrogenase 2 activation. Cardiol. Pharmacol. 678, 32-38

Heitzer T., Finckh B., Albers S., Krohn K., Kohlschutter A., Meinertz T. (2001): Beneficial effects of alpha-lipoic acid and ascorbic acid on endothelium-dependent, nitric oxide-mediated vasodilation in diabetic patients: relation to parameters of oxidative stress. Free Radic. Biol. Med. 31, 53-61
http://dx.doi.org/10.1016/S0891-5849(01)00551-2

Hjalmarson A., Gilpin E. A., Kjekshus J., Schieman G., Nicod P., Henning H., Ross J. (1990): Influence of heart rate on mortality after acute myocardial infarction. Am. J. Cardiol. 65, $547-553$

http://dx.doi.org/10.1016/0002-9149(90)91029-6

Hurst R. T., Lee R. W. (2003): Increased incidence of coronary atherosclerosis in type 2 diabetes mellitus: mechanisms and management. Ann. Intern. Med. 139, 824-834

http://dx.doi.org/10.7326/0003-4819-139-10-20031118000010

Jay D., Hitomi H., Griendling K. K. (2006): Oxidative stress and diabetic cardiovascular complications. Free Radic. Biol. Med. 40, 183-192 http://dx.doi.org/10.1016/j.freeradbiomed.2005.06.018

Juranek I., Horakova L., Rackova L., Stefek M. (2010): Antioxidants in treating pathologies involving oxidative damage: an update on medicinal chemistry and biological activity od stobadine and related pyridoindoles. Cur. Med. Chem. 17, 552-570 http://dx.doi.org/10.2174/092986710790416317

Kjekshus J. (1986): Importance of heart rate in determining betablocker efficacy in acute and long-term acute myocardial infarction intervention trials. Am. J. Cardiol. 57, 43F-49F http://dx.doi.org/10.1016/0002-9149(86)90888-X

Knezl V., Kyselova Z., Zurova-Nedelcevova J., Navarova J., Tribulova N., Drimal J. (2006): Effect of acetylcholine and ischae$\mathrm{mia} /$ reperfusion injury on the heart of rats with STZ-induced experimental diabetes. Neuro. Endocrinol. Lett. 27, 144-147

Kucharska J., Stefek M., Sotnikova R., Braunova Z., Gvozdjakova A. (2000): Disturbances in heart and skeletal muscle coenzyme $\mathrm{Q}$ and alpha-tocopherol levels in streptozotocin-diabetic rats. Effect of antioxidant stobadine. Chem. Pap. 94, 678-679

Kusama Y., Hearse D. J., Avkiran M. (1992): Diabetes and susceptibility to reperfusion-induced ventricular arrhythmias. J. Mol. Cell. Cardiol. 24, 411-421 http://dx.doi.org/10.1016/0022-2828(92)93195-P

Kyselova Z., Gajdosik A., Gajdosikova A., Ulicna O., Mihalova D., Karasu C., Stefek M. (2005): Effect of the pyridoindole antioxidant stobadine on development of experimental diabetic cataract and on lens protein oxidation in rats: comparison with vitamin E and BHT. Mol. Vis. 11, 56-65

Li C. J., Zhang Q. M., Li M. Z., Zhang J. Y., Yu P., Yu D. M. (2009): Attenuation of myocardial apoptosis by alpha-lipoic acid through suppression of mitochondrial oxidative stress to reduce diabetic cardiomyopathy. Chin. Med. J. 122, 2580-2586

Lomblin N., Fertin M., de Groote P., Bauters C. (2012): Cardiac remodeling and heart-failure after a first anterior maycardial infarction in patients with diabetes mellitus. J. Cardiol. Med. 13, 353-359 http://dx.doi.org/10.2459/JCM.0b013e328353694b

Mannucci E., Monami M., Lamanna C., Gori F., Marchionni N. (2009): Prevention of cardiovascular disease through glycemic control in type 2 diabetes: a meta-analysis of randomized clinical trials. Nutr. Metab. Cardiovasc. Dis. 19, 604-612 http://dx.doi.org/10.1016/j.numecd.2009.03.021

Martin-Gallan P., Carrascosa A., Gussinye M., Dominguez C. (2003): Biomarkers of diabetes-associated oxidative stress and antioxi- 
dant status in young diabetic patients with or without subclinical complications. Free Radic. Biol. Med. 34, 1563-1574 http://dx.doi.org/10.1016/S0891-5849(03)00185-0

Matejikova J., Kucharska J., Pancza D., Ravingerova T. (2008): The effect of antioxidant treatment and NOS inhibition on the incidence of ischaemia-induced arrhythmias in the diabetic rat heart. Physiol. Res. 57, S55-60

Okazaki T., Otani H., Shimazu T., Yoshioka K., Fujita M., Iwasaka T. (2001): Ascorbic acid and N-acetyl cysteine prevent uncoupling of nitric oxide synthase and increase tolerance to ischemia/reperfusion injury in diabetic rat heart. Free Radic. Res. 45, 1173-1183 http://dx.doi.org/10.3109/10715762.2011.605361

Paulson D. J. (1997): The diabetic heart is more sensitive to ischaemic injury. Cardiovasc. Res. 34, 104-112 http://dx.doi.org/10.1016/S0008-6363(97)00018-7

Rasamy R., Schaefer S. (1999): Inhibition of Na+-H+Exchanger Protects Diabetic and Non-Diabetic Hearts From Ischemic Injury: Insight into Altered Susceptibility of Diabetic Hearts to Ischemic Injury. J. Mol. Cel. Cardiol. 31, 785-797 http://dx.doi.org/10.1006/jmcc.1998.0908

Ravingerova T., Neckar J., Kolar F., Stetka R., Volkova K., Ziegelhoffer A., Styk J. (2001): Ventricular arrhythmias following coronary artery occlusion in rats: is the diabetic heart less or more sensitive to ischaemia? Basic Res. Cardiol. 96, 160-168 http://dx.doi.org/10.1007/s003950170066

Seghrouchni I., Drai J., Bannier E., Riviere J., Calmard P., Garcia I., Orgiazzi J., Revol A. (2002): Oxidative stress parameters in type I, type II and insulin-treated type 2 diabetes mellitus; insulin treatment efficiency. Clin. Chim. Acta 321, 89-96 http://dx.doi.org/10.1016/S0009-8981(02)00099-2

Skalska S., Kyselova Z., Gajdosikova A., Carasu C., Stefek M., Stolc S. (2008): Protective effect of stobadine on NCV in streptozotocin-diabetic rats: augmentation by vitamin E. Gen. Physiol. Biophys. 27, 106-114

Skalska S., Kucera P., Goldenberg Z., Stefek M., Kyselova Z., Jariabka P., Gajdosikova A., Klobucnikova K., Traubner P., Stolc S. (2010): Neuropathy in a rat model of mild diabetes induced by multiple low doses of streptozotocin: effects of the antioxidant stobadine in comparison with a high-dose $\alpha$-lipoic acid treatment. Gen. Physiol. Biophys. 29, 50-58 http://dx.doi.org/10.4149/gpb_2010_01_50

Skrzypiec-Spring M. (2007): Isolated heart perfusion according to Langendorff - still viable in the new millennium. J. Pharmacol. Toxicol. Methods. 55, 113-126 http://dx.doi.org/10.1016/j.vascn.2006.05.006

Sotnikova R., Gibala P. and Drimal J. (1985): Alpha-adrenolytic activity of the substance DH 1011. Bratisl. Lek. Listy 84, 536-541 (in Slovak)

Sotnikova R., Stefek M., Okruhlicova L., Navarova J., Bauer V., Gajdosik A., Gajdosikova A. (2001): Dietary supplementation of the pyridoindole antioxidant stobadine reduces vascular impairment in streptozotocin-diabetic rats. Methods Find. Exp. Clin. 23, 121-129

http://dx.doi.org/10.1358/mf.2001.23.3.627943

Stasko A., Ondrias K., Misik V., Szocsova H., Gergel D. (1990): Stobadine - a novel scavenger of free radicals. Chem. Pap. 44, 493-500

Stefek M., Sotnikova R., Okruhlicova L., Volkovova K., Kucharska J., Gajdosik A., Gajdosikova A., Mihalova D., Hozova R., Tribulova N., Gvozdjakova A. (2000): Effect of dietary supplementation with the pyridoindole antioxidant stobadine on antioxidant state and ultrastructure of diabetic rat myocardium. Acta Diabetol. 37, 111-117 http://dx.doi.org/10.1007/s005920070012

Stefek M., Gajdosik A., Tribulova N., Navarova J., Volkovova K., Weismann P., Gajdosikova A., Drimal J., Mihalova D. (2002): The pyridoindole antioxidant stobadine attenuates albuminuria, enzymuria, kidney lipid peroxidation and matrix collagen cross-linking in streptozotocin-induced diabetic rats. Methods Find. Exp. Clin. 24, 565-571

Tankova T., Koev D., Dakovska L. (2004): Alpha-lipoic acid in the treatment of autonomic diabetic neuropathy (controlled, randomized, open-label study). Rom. J. Intern. Med. 42, 457-464

Tosaki A., Engelman D. T., Engelman R. M., Das D. K. (1996): The evolution of diabetic response to ischaemia/reperfusion and preconditioning in isolated working rat hearts. Cardiovasc. Res. 31, 526-536

Zhang L. Q., Parratt J. R., Beastall G. H., Pyne N. J.; Furman B. L. (2002): Streptozotocin diabetes protects against arrhythmias in rat isolated hearts: role of hypothyroidism. Europ. J. Pharmacol. 435, 269-276 http://dx.doi.org/10.1016/S0014-2999(01)01398-X

Ziegler D. (2008): Treatment of diabetic neuropathy and neuropathic pain: how far have we come? Diabetes Care 31, S255-261

Received: July 23, 2012

Final version accepted: January 9, 2013 